\title{
Sistemas de Numeração: Evolução Histórica, Fundamentos e Sugestões para o Ensino
}

\author{
Numeral Systems: Historical Development, Foundations and Suggestions for \\ Teaching
}

\author{
Aroldo Eduardo Athias Rodrigues ${ }^{1}$ e Hugo Alex Diniz ${ }^{2}$ \\ ${ }^{1}$ Mestre em Matemática, Professor Adjunto, Universidade Federal do Oeste do Pará, Brasil \\ aroldoeduardo@yahoo.com.br \\ ${ }^{2}$ Doutor em Matemática, Professor Adjunto da Universidade Federal do Oeste do Pará , Brasil \\ halexdiniz@gmail.com
}

\begin{abstract}
Resumo
São os sistemas de numeração que permitem a representação dos números, os quais, juntamente com as formas, constituem o principal objeto de estudo da Matemática. É através deles também que se podem justificar os procedimentos adotados para efetuar as quatro operações aritméticas básicas. É, portanto, extremamente importante que o professor de Matemática tenha uma compreensão profunda do funcionamento dos sistemas de numeração, em especial, do Sistema de Numeração Posicional Decimal (SNPD). Neste artigo tratamos das propriedades dos sistemas de numeração, em especial aquelas relacionadas com os critérios de divisibilidade e a representação dos números reais em sistemas posicionais. Abordamos o tema a partir de três aspectos principais: sua evolução histórica; as propriedades puramente matemáticas dos sistemas de numeração posicionais; e a forma como o professor pode utilizar os dois aspectos anteriores em suas aulas.
\end{abstract}

Palavras-chave: Sistemas de numeração. Critérios de divisibilidade. Base

\begin{abstract}
Numeral systems allow the representation of numbers, which, together with the forms, constitute the main object of studying of Mathematics. It is also through them that someone can justify the procedures used to perform the four basic arithmetic operations. It is therefore extremely important that the math teacher has a deep understanding of the functioning of numeral systems, in especial, the Decimal Positional Numeral System (DPNS). In this article, we study the properties of numeral systems, in particular those related to the criteria of divisibility and the representation of real numbers in positional systems. We address the topic from three main aspects: its historical evolution; purely mathematical properties of positional numeral systems; and how the teacher can use the two previous aspects in their classes.
\end{abstract}

Keywords: Numeral systems. Criteria of divisibility. Base 


\section{Introdução}

A necessidade de representar os números levou os homens à criação de diversos sistemas com essa finalidade, chamados sistemas de numeração. $O$ estudo de tais sistemas é o objetivo principal deste artigo, que procura reunir diferentes aspectos relacionados ao estudo deste tema, como seu desenvolvimento histórico, explicitação de propriedades importantes ou curiosas e sugestões para abordá-lo na escola.

Uma vez que os números ocupam um papel central na Matemática, todo aquele que deseje um dia ensinar ou fazer Matemática deve compreender a maneira pela qual os números são representados, o que leva ao estudo dos sistemas de numeração. Essa maneira, aliás, exerce também grande influência na realização das operações com estes números, portanto, encontrar uma boa notação para eles foi de suma importância para o desenvolvimento da Matemática.

O desenvolvimento de um sistema de numeração eficiente, como é o caso do Sistema de Numeração Posicional Decimal (SNPD), não foi algo que ocorreu rapidamente e, embora estejamos habituados com o seu uso, nem sempre os homens dominaram as regras que governam seu funcionamento, em especial, o princípio de posição. $\mathrm{O}$ fato de já termos automatizado muitas de suas propriedades, simplesmente utilizando-as, sem nos preocuparmos com o porquê de funcionarem, pode nos levar a crer que um estudo do SNPD é algo simplório. Porém, quem pensa dessa maneira, ignora certamente o fato de que os homens levaram milênios para poder desenvolvê-lo.

\section{Conceitos básicos}

Embora algumas vezes as pessoas utilizem indistintamente as palavras número e numeral, estes termos representam dois conceitos diferentes. Numeral é qualquer símbolo (gráfico ou não) utilizado para representar um número, que é a quantidade em si.

Também existe diferença entre os conceitos de numeral e algarismo. Podemos dizer que os algarismos são as unidades constituintes do numeral escrito, da mesma forma que as letras são as unidades constituintes da palavra escrita.
Para melhor compreender essa diferença, observe a frase abaixo:

“O numeral 365 é composto de três algarismos: o 3, o 6 e o 5".

É como se disséssemos:

"A palavra BOLA é composta das letras B, O, L e A".

Por essa analogia, podemos dizer que os algarismos são as letras com que escrevemos os numerais.

Ao longo da história os povos encontraram diversas formas de representar os números. Os incas, na América do Sul, por exemplo, conseguiam representá-los através de diferentes tipos de nós feitos em cordas, o quipu. E antes disso, na região da Mesopotâmia, os sumérios fabricavam pequenos objetos de barro que eram efetivamente seus numerais. Resumindo, a mente criativa do homem não se limitou às palavras, nem mesmo esperou o desenvolvimento da escrita, quando precisou encontrar meios para representar os números (IFRAH, 1997).

Chamamos de sistema de numeração qualquer sistema de representação dos números. Como era de se esperar, diferentes povos desenvolveram diferentes sistemas de numeração, os quais foram estruturados de maneira bastante diversa. Tais sistemas, embora diferentes, apresentavam algumas características em comum, características essas que discutiremos mais adiante.

\section{Caminhos dos povos para a representação do números}

Estamos tão habituados com o SNPD que, algumas vezes, deixamos de perceber que outras formas de representar os números são também possíveis e, não fosse pela enorme difusão do SNPD na atualidade seriam, até mesmo, viáveis.

Podemos dizer que os sistemas de numeração diferem-se uns dos outros sob dois aspectos principais: quanto à base e quanto à estrutura.

Para entendermos o que vem a ser a base de um sistema de numeração imagine que você queira contar quantos traços verticais há a seguir:

|||||||||||||||||||||||||||||||||||||||||||||||||||||||||||||||||||| 
Uma forma de facilitar o processo de contagem seria fazer um traço horizontal sobre cada quinze traços verticais, você certamente será capaz de dizer quantos traços verticais há na coleção anterior, desde que você esteja ciente de que um traço horizontal corresponde a quinze verticais e que a quantidade de traços horizontais não seja muito elevada.

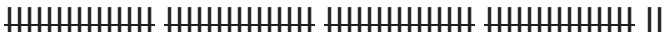

Contar agrupamentos é mais fácil do que contar unidades, desde que todos os grupos possuam a mesma quantidade de elementos e que esta quantidade seja conhecida.

Nada impede que os quinze traços cortados sejam substituídos por outro símbolo qualquer que represente tal quantidade, digamos que o símbolo escolhido fosse $\mathrm{H}$, sugerido pela forma desta letra, que traz a mente imagem de um grupo (par) de traços verticais cortados por outro horizontal. Assim, voltando ao exemplo dado anteriormente teríamos HHHHII como uma representação do número 62 .

Mantendo essa simbologia, como poderíamos representar o número 274? A resposta é HHHHHHHHHHHHHHHHHHIIII. Note que, neste caso, o símbolo $\mathrm{H}$ se repete tantas vezes que não conseguimos saber, de imediato, quantas vezes esse símbolo aparece. Uma alternativa para contornar este problema é a criação de um novo símbolo, digamos $\Delta$, para representar um agrupamento de 15 símbolos $\mathrm{H}$. Desta forma, o número 274 passaria a ser representado por $\Delta$ HHHIIII. Caso o símbolo $\Delta$ aparecesse uma grande quantidade de vezes, um novo símbolo poderia ser criado e assim por diante.

Note que poderíamos fazer com que o símbolo $\Delta$ representasse $14,16,18$ ou outra quantidade qualquer de símbolos $\mathrm{H}$, porém, convencionar o uso da mesma quantidade na passagem de um símbolo para outro evita o inconveniente de ter de especificar como deve se dar cada passagem. A quantidade adotada para efetuar cada agrupamento é o que denominamos base do sistema de numeração. No exemplo dado, criamos um sistema de numeração de base 15 , cujos algarismos são I, H e $\Delta$.
No que diz respeito à base, um sistema de numeração pode ser binário, decimal, vigesimal, sexagesimal ou de qualquer outro tipo, conforme o número inteiro positivo maior do que 1 que utilizemos para formar os numerais. No caso dos sistemas citados, suas bases são, respectivamente, 2, 10, 20 e 60. Quanto à estrutura, os sistemas de numeração podem ser classificados em dois grandes grupos: posicionais e não posicionais. Os sistemas pertencentes a este último grupo podem ainda ser subdivididos em sistemas do tipo aditivo ou do tipo híbrido ${ }^{1}$ (RODRIGUES, 2013).

Conhecer sistemas de numeração que diferem entre si pela base ou pela estrutura possibilita uma melhor compreensão do funcionamento do SNPD e, portanto, das operações efetuadas através dele. Assim, com o objetivo de transmitir uma melhor ideia das diferenças existentes entre os sistemas de numeração adotados pelos povos, apresentaremos aqui alguns exemplos de sistemas de numeração utilizados por eles e forneceremos sua classificação. Contudo, para não passar a falsa impressão de que esses povos adotaram, cada um deles, um único sistema de numeração imutável, é preciso dizer que, com o passar do tempo, assim como os hábitos e a cultura dos povos se modificam, também a maneira pela qual esses povos representaram os números modificou-se. Desta forma, dizendo que o sistema de numeração que era adotado pelos povos da Mesopotâmia era posicional, queremos dizer que um dos sistemas de numeração adotados por esse povo, em um de seus estágios de desenvolvimento, possuía essa estrutura. $\mathrm{Ou}$, quando dizemos, que os egípcios possuíam um sistema do tipo aditivo, fazemos menção a um dos vários sistemas desenvolvidos por essa civilização ao longo dos séculos (IFRAH, 1997).

Para citar dois sistemas de numeração diferentes, porém ambos decimais do tipo aditivo, consideremos os sistemas hieroglífico egípcio e alfabético grego. Na Figura 1, apresentamos os algarismos utilizados pelos egípcios para representar diferentes potências

\footnotetext{
${ }^{1}$ Ifrah (1997, p.692-703) apresenta uma classificação mais minuciosa dos sistemas de numeração, porém diferente da que fazemos aqui.
} 
de dez e na Figura 2 o número 4.507, tal como seria representado por este povo.

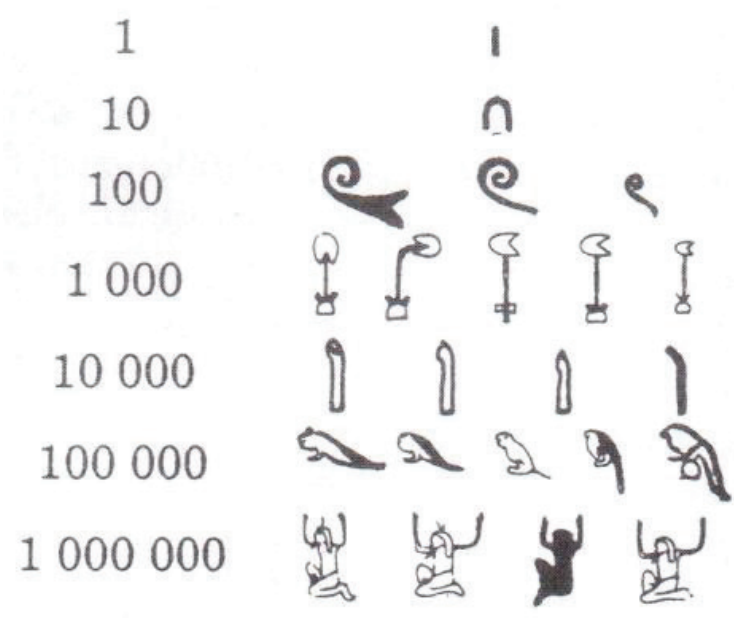

Figura 1: Algarismos hieroglíficos egípcios. Fonte: IFRAH, 2005, p. 158.

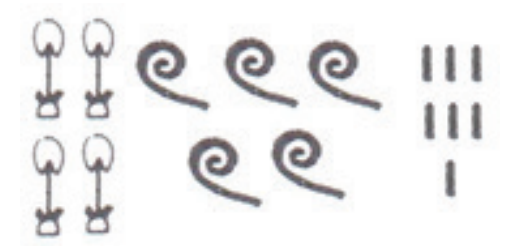

Figura 2: Representação do número 4057 por meio do sistema hieroglífico egípcio.

Fonte: Adaptado de IFRAH, 2005, p. 158.

Observa-se que o número 4.507 é formado pela simples adição do valor dos algarismos que representam os milhares, as centenas e as unidades, os quais são repetidos tantas vezes quantas forem necessárias para atingir a quantidade que se deseja representar. Daí o termo tipo aditivo para representar tais sistemas.

Os gregos deram um passo adiante com seu sistema alfabético. Eles perceberam que não seria necessário repetir diversas vezes o mesmo algarismo se atribuíssem símbolos diferentes para cada quantidade de unidades, dezenas ou centenas. Assim, no sistema grego alfabético os números de 1 a 9, os múltiplos de 10 até 90 e de 100 até 900 possuíam símbolos específicos que os representavam (EVES, 2004). É claro que isto criava uma grande quantidade de símbolos para serem memorizados, porém os gregos contornaram este problema utilizando as letras de seu próprio alfabeto como algarismos. Além destas, também eram utilizados três símbolos obsoletos $\zeta$ (stigma), Q (koppa) e $\ngtr$ (sampi).

Desta forma, quando os gregos desejavam representar um número como 542, utilizavam, tal como nós hoje em dia, apenas três algarismos, escrevendo $\varphi \mu \beta$, ou, em alguns casos, como o do número 701, até menos algarismos que nós, escrevendo $\psi \alpha$. Contudo, embora sua notação conseguisse, em alguns casos, ser mais compacta que a atual, essa pequena vantagem, como veremos, é ínfima diante das grandes desvantagens que esse sistema do tipo aditivo apresenta em relação aos sistemas do tipo posicionais.

Dentre os sistemas do tipo aditivo, o mais conhecido é o sistema de numeração romano, que dispensa apresentações. Embora seja decimal, como o eram os dois sistemas precedentes, este possui o número 5 como base auxiliar. Assim, os romanos encontraram uma solução diferente da dos gregos para evitar a repetição de um mesmo algarismo diversas vezes. Assim, se queriam expressar o número 59, ao invés de escreverem XXXXXIIIIIIIII, escreviam simplesmente LVIIII, ou seja, cada vez que um algarismo aparecia repetido cinco vezes ele era substituído por um símbolo correspondente, neste caso, L e V em substituição dos cinco $\mathrm{X}$ e de cinco dos nove I. Talvez cause estranhamento ao leitor a representação que demos para o número 59 como LVIIII ao invés de LIX. Ocorre que o princípio segundo o qual devemos efetuar a subtração, ao invés da adição, quando um algarismo é posto antes de outro cujo valor lhe é superior, é conhecido como princípio subtrativo e era pouco utilizado pelos romanos, sendo seu uso consagrado apenas nos tempos modernos (EVES, 2004).

Como exemplo de um sistema do tipo híbrido temos o sistema tradicional chinês, que ainda hoje é utilizado na China ao lado do SNPD para representar os números, muito embora seja este último aquele utilizado para realização dos cálculos. No sistema tradicional chinês, que também é decimal, há algarismos especiais tanto para representar os números de um a nove, quanto para as primeiras potências de dez, os quais estão representados na Figura 3, juntamente com o numeral 5625. 


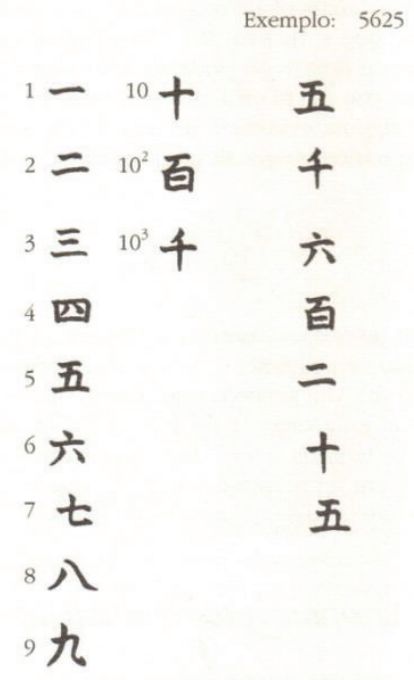

Figura 3: Algarismos do sistema tradicional chinês e exemplificação do número 5625. Fonte: EVES, 2004, p. 34.

Ora, o número 5.625 é precisamente

$$
5 \times 10^{3}+6 \times 10^{2}+2 \times 10+5,
$$

assim, o que o sistema tradicional chinês faz é deixar implícitos os sinais de adição e multiplicação em seus numerais. É justamente por combinar os princípios aditivo e multiplicativo que os sistemas deste tipo são chamados de híbridos. Sobre os sistemas aditivos estes apresentam a vantagem de evitar várias repetições do mesmo algarismo.

Os sistemas de numeração posicionais representam o último estágio do desenvolvimento dos sistemas de numeração. Eles são caracterizados pelo princípio de posição, segundo o qual os algarismos assumem valores relativos à posição que ocupam no numeral, daí o termo posicional que designa este tipo de sistema.

Não é difícil perceber que os sistemas do tipo híbrido estão a apenas um passo dos sistemas do tipo posicional, isto porque o hábito de escrever os algarismos respeitando sempre a ordem da maior para a menor grandeza em algum momento revelará a inutilidade de exibir as potências de dez, desde que se tome o cuidado de marcar de alguma maneira as grandezas ausentes.

Eis o que possibilitou o próximo passo na evolução dos sistemas de numeração: a invenção do zero. A criação de um símbolo para representar o vazio é, sem sombra de dúvida, um passo decisivo para o bom funcionamento dos sistemas de numeração posicionais. Para falar deste tipo de sistema vamos conhecer um pouco mais sobre o sistema numeração desenvolvido pelos povos que habitaram a região da Antiga Mesopotâmia. Estes povos, curiosamente escolheram o número 60 como base de seu sistema de numeração. Há diversas hipóteses para tentar explicar o que levou estes povos a adotarem uma base tão elevada, a que nos parece mais provável é aquela expressa por (IFRAH, 1997) (1997), segundo a qual, antes da dominação suméria da Baixa Mesopotâmia, esta região já era habitada e uma das duas culturas, os nativos ou os estrangeiros, adotava a base cinco para seu sistema de numeração, enquanto o sistema de numeração da outra repousava sobre a dúzia. Segundo o mesmo autor, é possível contar uma dúzia com apenas uma mão, utilizando as doze falanges e o polegar como contador. Esta técnica é ainda hoje utilizada no Egito, Síria, Iraque, Irã, Afeganistão, Paquistão e em certas regiões da Índia e está ilustrada pelas Figuras 4 e 5.

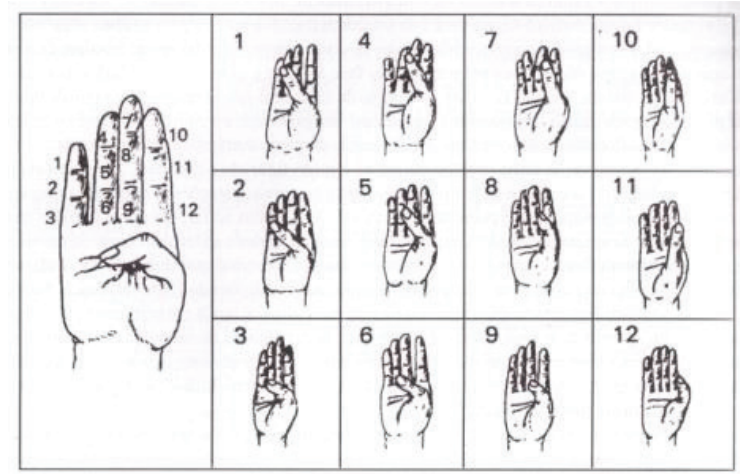

Figura 4: Contando uma dúzia com uma única mão.

Fonte: IFRAH, 1997, p. 188.

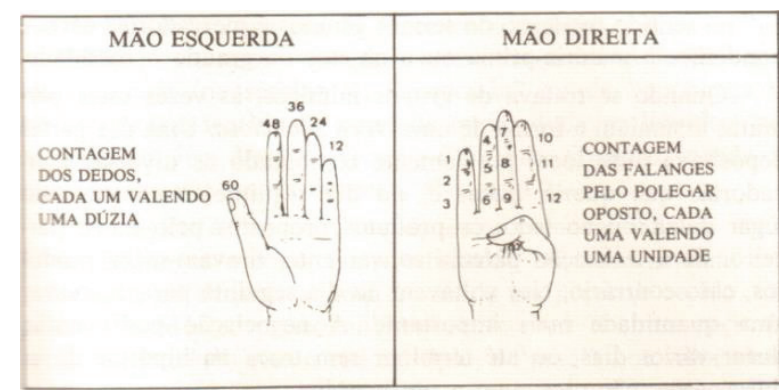

Figura 5: Contando até sessenta utilizando as duas mãos.

Fonte: IFRAH, 2005, p. 71.

Embora um sistema posicional sexagesimal exigisse, em princípio, a criação de 60 
algarismos, os povos que adotaram tal sistema souberam muito bem como contornar esse problema escrevendo os numerais de 1 a 59 através de um sistema decimal do tipo aditivo. Assim, na prática, os mesopotâmicos possuíam apenas dois algarismos: para a unidade e para a dezena, ambos produzidos através de marcas feitas com uma cunha em pequenos blocos de argila (IFRAH, 1997).

Quanto ao zero mesopotâmico, talvez o primeiro da história, não surgiu do dia para a noite. Inicialmente era costume marcar as casas vazias deixando um espaço maior entre os algarismos, o que efetivamente poderia gerar problemas quando duas casas consecutivas fossem vazias ou quando não houvesse unidades no numeral. Esse problema só foi superado por volta do século III a.C., com a introdução de símbolos, como os mostrados na Figura 6. Estava criado o zero (IFRAH, 2005).

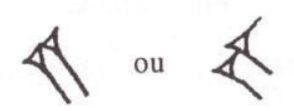

Figura 6: Representações do número zero utilizadas pelos sábios mesopotâmicos.

Fonte: IFRAH, 1997, p. 297.

Outros povos, como os maias, por exemplo, que adotavam um curioso sistema vigesimal com uma anomalia nas unidades de 3 a ordem (o algarismo aí colocado representava $360=20 x$ 18 e não $400=20^{2}$, como seria de se esperar em um sistema vigesimal) também desenvolveram sistemas posicionais. Assim como os povos da Mesopotâmia, os maias representavam seus algarismos de 1 a 19 através de um sistema do tipo aditivo, só que quinário, em que pontos representavam unidades e traços verticais ou horizontais equivaliam a cinco unidades. Também eles inventaram e utilizaram o zero (IFRAH, 2005).

Embora hoje nos pareça trivial representar os números através do SNPD, no decorrer da história apenas mais três povos, além dos mesopotâmicos e dos maias, foram capazes de dominar o princípio posicional: os chineses, os hindus e a nossa civilização. Muitos dos avanços da Matemática só foram possíveis através dessa invenção. Assim, garantir que nossos alunos conheçam esses fatos, além de transmitir uma visão mais humana da Matemática, melhora a compreensão sobre um tema que, historicamente, já demonstrou sua importância.

\section{Sistemas de numeração posicionais}

Em sistemas posicionais, é possível representar qualquer número, por maior que seja, com uma quantidade finita de símbolos. Além disso, os números representados por meio deles se prestam a realização das quatro operações aritméticas básicas.

Vejamos como se dá a representação dos números nesse tipo de sistema. Para isso, considere a Figura 7.

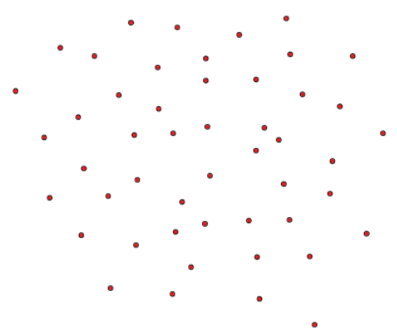

Figura 1: Quarenta e nove pontos dispersos. Fonte: RODRIGUES, 2013, p. 42.

Depois de efetuar corretamente a contagem, podemos afirmar que há 49 pontos nessa figura.

Mas, embora tenhamos representado essa quantidade de pontos por um 4 seguido de um 9, observamos que não há, nesta nuvem de pontos, o menor vestígio das quantidades representadas por esses dois algarismos. Por que então esta quantidade de pontos está sendo representada por um numeral constituído desses algarismos? A Figura 8 responde essa pergunta.

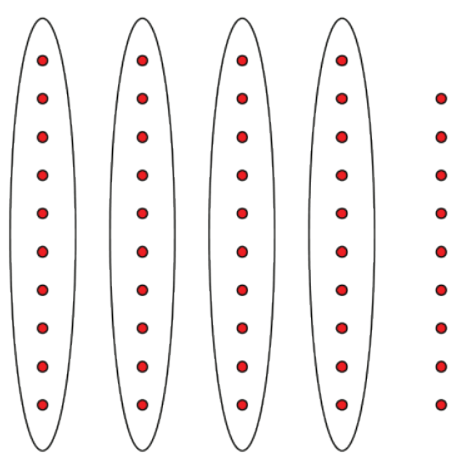

Figura 2: Quarenta e nove pontos agrupados de dez em dez.

Fonte: RODRIGUES, 2013, p. 42. 
Temos aí 49 pontos, não mais dispersos, mas agrupados de dez em dez, facilitando a contagem. Vemos, agora, claramente, o porquê da escolha dos algarismos 4 (quatro dezenas) e 9 (nove unidades). Assim, 49 é um numeral que pode perfeitamente representar a quantidade de pontos da Figura 7 e para entender o significado desta representação basta que saibamos que número foi escolhido para realizar os agrupamentos, ou seja, a base do sistema de numeração.

Note, contudo, que não há nada que nos impeça de realizarmos o agrupamento dos pontos de outra maneira, como ilustra a Figura 9.

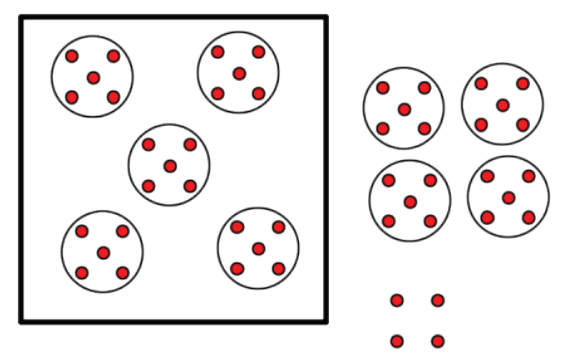

Figura 3: Quarenta e nove pontos agrupados de cinco em cinco.

Fonte: RODRIGUES, 2013, p. 44.

A Figura 9 sugere um novo numeral para representar o número 49, ou seja, 144. Esse numeral se presta tão bem quanto o numeral " 49 " para representar a quantidade de pontos, desde que saibamos que os agrupamentos foram realizados de cinco em cinco e não de dez em dez. Porém, ao contrário do que acontece com a base 10, cuja aceitação generalizada nos permite realizar a interpretação correta do número associado ao numeral sem a necessidade de explicitar a base, precisamos aqui indicar que a base utilizada para efetuar os agrupamentos foi a base 5 . Isso pode ser feito indexando a base ao numeral. Neste caso temos $144_{5}$.

Chamaremos representações como a das Figuras 8 e 9 de diagramas de pontos. Observe que algumas regras, devem ser utilizadas na montagem desses diagramas. São elas:

Regra 1. Em um sistema de numeração posicional, todos os algarismos valem menos do que a base.

Regra 2. Na montagem de um diagrama de pontos que representa um número em um sistema de numeração posicional de base $b$, $a$ quantidade de vezes que um tipo de grupo aparece isolado deve ser sempre inferior $a b$ e, caso haja algum grupo aparecendo $b$ vezes ou mais, $b$ desses grupos devem ser reunidos em um novo tipo de grupo.

Outra maneira, mais prática que o diagrama de pontos, para obter a representação de certa quantidade em uma base não decimal é o método das divisões sucessivas, o qual consiste em efetuar a divisão inteira do número dado na base dez pela base $b$ do novo sistema de numeração; tomar o quociente da divisão e dividi-lo também por $b$, repetindo este processo até que o quociente obtido torne-se menor do que $\mathrm{b}$; feito isto, tomam-se o último quociente $\mathrm{e}$ os restos obtidos em cada uma das divisões, escrevendo-os, da esquerda para a direita, na ordem inversa de seu aparecimento ao longo do processo.

A Figura 10 exemplifica esse processo, mostrando como escrever o número 436 na base ternária.

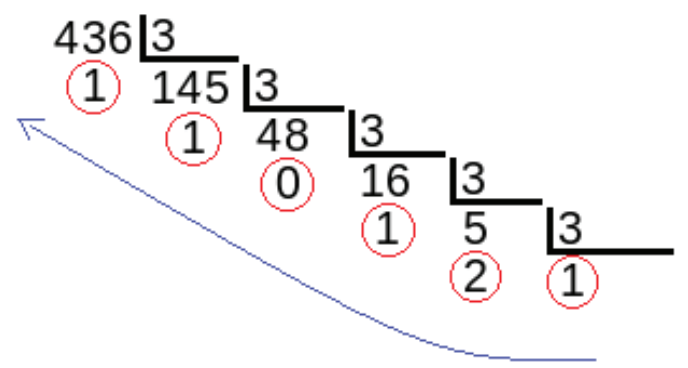

Figura 4: Processo de conversão do número 436 para a base três.

Fonte: RODRIGUES, 2013, p. 50.

Assim, o numeral que corresponde ao número 436 no sistema de numeração ternário é $121011_{3}$.

Observe ainda que este processo preserva as Regras 1 e 2 antes comentadas. Mas o que fazer se a base for maior que 10, já que, neste caso podem surgir restos maiores ou iguais a $10 \mathrm{e}$ que dispomos apenas dos dez algarismos indoarábicos conhecidos? Uma resposta para esta questão é criar novos símbolos ou, como usualmente se faz, utilizar a sequência das letras do alfabeto para dar continuidade à sequência dos algarismos. Assim, por exemplo, os algarismos da base 13 são $0,1,2,3,4,5,6$, 7, $8,9, A, B$ e $C$, em que $A=10, B=11$ e $C=12$. 
O processo inverso, isto é, descobrir qual o número associado a um numeral representado em uma base não decimal é ainda mais simples. Para melhor compreendê-lo observe que

$$
532=5 \cdot 10^{2}+3 \cdot 10^{1}+2 \cdot 10^{0}
$$

e que o fato de aparecerem potências de dez em cada termo do segundo membro está associado ao fato de 532 estar expresso no sistema decimal. Assim, o valor de um numeral como $2 D 5 E_{15}$, pode ser obtido da mesma forma, desde que seus algarismos multipliquem as potências de 15 adequadas ao invés de potências de dez. Desse modo, podemos fazer

$2 D 5 E_{15}=2 \cdot 15^{3}+13 \cdot 15+5 \cdot 15^{1}+14 \cdot 15^{0}$ $2 D 5 E_{15}=2 \cdot 3.375+13 \cdot 225+5 \cdot 15+14 \cdot 1$

$2 D 5 E_{15}=6.750+2.925+75+14$

$2 D 5 E_{15}=9.764$.

Note que os algarismos D e E foram substituídos por seus valores correspondentes 13 e 14, respectivamente.

Em geral o estudo dos sistemas de numeração é interrompido neste ponto. Neste artigo, entretanto, gostaríamos de ir um pouco além, tratando de algumas propriedades interessantes relacionadas com a representação dos números em sistemas posicionais que não são necessariamente decimais. Tais propriedades estão relacionadas com os critérios de divisibilidade de números inteiros e a representação de números reais em outros sistemas posicionais. Pensamos que o conhecimento destes fatos pode ajudar o professor a ter uma visão mais ampla a respeito do tema, compreendendo melhor certos aspectos do funcionamento do SNPD, adquirindo desta forma maior segurança para discorrer sobre este tema, ou outros relacionados com ele, com seus alunos.

\section{Critérios de divisibilidade em sistemas posicionais}

A partir de agora estabeleceremos alguns resultados que generalizam os critérios de divisibilidade para sistemas de numeração posicionais que não sejam necessariamente decimais. As demonstrações destes resultados não serão feitas aqui, para aqueles que desejarem ter acesso às mesmas a indicamos a leitura de Rodrigues (2013), em cujo capítulo 3 estas estão feitas de maneira detalhada.

Vamos aos teoremas, o primeiro dos quais explicita sob que circunstâncias um número é divisível pela base do sistema de numeração.

Teorema 1. Um número é divisível pela base do sistema de numeração se, e somente se, terminar em 0 .

Teorema 2. Se a base de um sistema de numeração é par, então um número é divisível pela metade $m$ da base se, e somente se, ele termina em 0 ou m.

Na base 10, todo número terminado em 0 ou 5 é múltiplo de 5 , justamente porque 5 é metade de 10. Agora, se 137, 450, A7, 60 e 35 são números expressos na base 14, então são, todos eles, com exceção do último, múltiplos de 7 , já que os quatro primeiros terminam em 0 ou 7 . De fato, esses números representam, na base dez, $\quad 245=35 \times 7, \quad 854=122 \times 7, \quad 147=$ $21 \times 7,84=12 \times 7$ e 47 , respectivamente.

Teorema 3. Seja d um divisor da base de um sistema de numeração, então um número é divisível por d se, e somente se, terminar em um múltiplo de $d$.

O número 10 só possui dois divisores próprios, o 2 e o 5, portanto, no sistema decimal, é a esses números que se aplica esse critério. De fato, os únicos múltiplos de 2 que possuem um único algarismo são $0,2,4,6$ e 8 , justamente as terminações que tornam um número par, e os de 5 são 0 e 5 .

Consideremos agora a base $15=3 \times 5$. Nesta base um número será múltiplo de 3 caso termine em $0,3,6,9$ ou $\mathrm{C}$ e de 5 caso termine em 0,5 ou A. Logo, $45 C_{15}$ é um múltiplo de 3 . De fato,

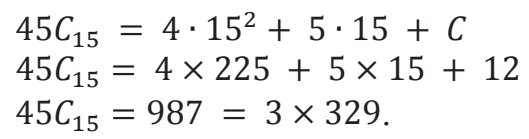

Teorema 4. Seja d um divisor da base de um sistema de numeração, então um número é divisível por $d_{n}$ se, e somente se, os $n$ últimos algarismos 
desse número formam, na ordem em que aparecem, um múltiplo de $d_{n}$.

Este teorema justifica os critérios de divisibilidade dos números 4 e 8 , visto que $4=$ $2^{2}, 8=2^{3}$ e 2 é divisor de 10 . Assim, para sabermos que o número 467.545.416 é divisível por 8 não precisamos realizar toda a divisão, sendo suficiente para tanto constatar que seus três últimos dígitos, 416, na ordem em que aparecem, formam um múltiplo de 8 , a saber $8 \times 52$. Todavia, o grande mérito do teorema das potências não reside aí, e sim no fato de que nos revela que qualquer potência de 2 ou de 5 goza desta propriedade. Assim, por exemplo, um número só será múltiplo de $25=5^{2}$ se terminar em 00 , 25, 50 ou 75 , visto que esses são os únicos múltiplos de 25 que têm dois algarismos ou menos.

Teorema 5. Um número é divisível pelo antecessor a da base de um sistema de numeração se, e somente se, a soma dos algarismos que formam este número for um múltiplo de a.

$\mathrm{Na}$ base 10, trata-se aí do critério de divisibilidade do número 9 , segundo o qual um número é divisível por 9 se a soma de seus algarismos também o for.

Podemos garantir que o número $96.643 .758_{13}$ é um múltiplo de 12 se a soma de seus algarismos, efetuada utilizando-se a tabuada da base 13, resultar em um múltiplo de 12. Vejamos,

$9_{13}+6_{13}+6_{13}+4_{13}+3_{13}+7_{13}+5_{13}+8_{13}=$ $=\left[\left(9_{13}+6_{13}\right)+\left(6_{13}+4_{13}\right)\right]$

$+\left[\left(3_{13}+7_{13}\right)+\left(5_{13}+8_{13}\right)\right]=$

$=\left[12_{13}+A_{13}\right]+\left[A_{13}+10_{13}\right]=$

$=1 C_{13}+1 A_{13}=$

$=39_{13}=48=4 \times 12$.

Como vimos $39_{13}$ é um múltiplo de 12, porém, em caso de dúvida, pode-se repetir o processo. Assim, temos $3_{13}+9_{13}=C_{13}$ e como $C_{13}=12$, concluímos que o número $96.643 .758_{13}$ é, realmente um múltiplo de 12 . De fato, $\quad 96.643 .758_{13}=596.047 .356=12 \times$ 49.670.613.

Teorema 6. Seja $p$ um divisor do antecessor da base de um sistema de numeração, então um número é divisível por $p$ se, e somente se, a soma dos algarismos que formam este número for um múltiplo de $p$.

Na base 10, este é o critério de divisibilidade do número 3, o qual é o único divisor próprio de 9 .

$\mathrm{Na}$ base 13, por exemplo, esse critério pode ser aplicado ao número 4, que é um divisor de 12. Assim, o número $B 47 A_{13}$ é um múltiplo de 4 , pois $\left(B_{13}+4_{13}\right)+\left(7_{13}+A_{13}\right)=12_{13}+14_{13}=$ $26_{13}=32=4 \times 8$.

Teorema 7. Um número é divisível pelo sucessor $s$ da base de um sistema de numeração se, e somente se, a diferença entre a soma dos algarismos de ordens de unidades pares e a soma dos algarismos de ordens de unidades ímpares for um múltiplo de s.

Eis, quando aplicado à base 10, o critério de divisibilidade do número 11 . O número 9.677.613, por exemplo, é múltiplo de 11, pois 9 $+7+6+3=25,6+7+1=14$ e $25-14=11$.

Observe que $4642_{7}=1696=8 \times 212$. De fato, utilizando a tabuada da base 7 , temos $\left(4_{7}+4_{7}\right)-\left(6_{7}+2_{7}\right)=11_{7}-11_{7}=0_{7}$, que é múltiplo de qualquer número, inclusive de 8 .

Teorema 8. Seja q um divisor do sucessor da base de um sistema de numeração, então um número é divisível por q se, e somente se, a diferença entre a soma dos algarismos de ordens de unidades pares e a soma dos algarismos de ordens de unidades ímpares for um múltiplo de q.

Este teorema não se aplica a base 10, visto que não há divisores próprios de 11 .

Em um sistema de base 14, esse critério aplica-se aos números 3 e 5, que são os divisores de 15 , que é o sucessor de 14 . Assim, $D 377_{14}$ é um múltiplo de 5 , pois $\left(D_{14}+7_{14}\right)-$ $\left(3_{14}+7_{14}\right)=16_{14}-A_{14}=A_{14}$, e como $A_{14}=10$, que é múltiplo de 5 , também $D 377_{14}$ é um múltiplo de 5. Realmente, $D 377_{14}=36.365$, que como sabemos, pelo critério de divisibilidade de 5 na base 10, é um múltiplo de 5, pois termina em 5 .

Os teoremas vistos anteriormente nos permitem encontrar critérios de divisibilidade em sistemas de numeração posicionais que não sejam necessariamente decimais. Além disso, quando adquirimos uma visão mais ampliada sobre qualquer assunto, retornamos aos casos 
particulares com maior propriedade. Assim, podemos vislumbrar nuances que sem essa visão ampliada não seríamos capazes de perceber, como o fato de que o critério de divisibilidade do 2 e do 5 são, em essência o mesmo critério e que decorrem do fato de que esses números são divisores de 10 , ou que o critério de divisibilidade do 9 é o que é em virtude de 9 ser o antecessor de 10 e que o 3 segue esse mesmo critério porque 3 é divisor de 9 e não o critério do 9 assemelha-se ao do 3 porque $9=3^{2}$, ou algo do gênero. E o mais importante, passamos a perceber que, enquanto a divisibilidade é uma propriedade intrínseca dos números, os critérios de divisibilidade dependem da relação destes com a base do sistema de numeração.

\section{Representação de números reais em sistemas posicionais}

Nesta seção, abordaremos a representação posicional dos reais em uma determinada base b. Mesmo para a base decimal, esse tema geralmente não é tratado nos cursos de Introdução à Análise Real, que é uma das únicas oportunidades de estudá-lo na graduação em Matemática.

Os Parâmetros Curriculares Nacionais (PCN) propõem como conteúdo para o ensino de Matemática no quarto ciclo:

O importante é que o aluno identifique o número irracional como um número de infinitas 'casas' decimais não-periódicas, identifique esse número com um ponto na reta, situado entre dois racionais apropriados, reconheça que esse número não pode ser expresso por uma razão de inteiros; conheça números irracionais obtidos por raizes quadradas e localize alguns na reta numérica, fazendo uso, inclusive, de construções geométricas com régua e compasso. (BRASIL, 1998)

Santos (2007) analisou 14 livros didáticos, utilizados na $7^{\text {a }}$ série do Ensino Fundamental, e mostrou que a grande maioria deles não atende à proposta dos $\mathrm{PCN}$ para a abordagem dos números irracionais. Em um dos livros analisados não foi encontrado nenhum registro sobre números irracionais ou reais, nem mesmo em outros volumes da coleção.
Ainda no Ensino Fundamental, o aluno é apresentado ao número $\pi$ (pi), sendo este um dos seus primeiros contatos com os números irracionais. Também são trabalhadas neste nível de ensino as raízes não exatas de inteiros, que se constituem em outros exemplos de irracionais. Já no Ensino Médio, o número e (número de Euler ou constante de Napier) aparece no estudo das funções elementares. Em nossa experiência com licenciandos em Matemática durante o curso de Introdução à Análise Real, vemos, que em sua maioria, além de não saberem demonstrar que esses números são irracionais, não conhecem outros exemplos de irracionais.

Um numeral no sistema posicional de base $b$ é dado por

$$
\left(a_{n} a_{n-1} a_{n-2} \cdots a_{2} a_{1} a_{0}, a_{-1} a_{-2} a_{-3} \cdots\right)_{b}
$$

onde $0 \leq a_{i}<b, \quad a_{i} \in \mathbb{Z}$, que representa o número real

$$
\begin{aligned}
x= & a_{n} b^{n}+a_{n-1} b^{n-1}+a_{n-2} b^{n-2}+\cdots+a_{2} b^{2}+ \\
& a_{1} b^{1}+a_{0} b^{0}+a_{-1} b^{-1}+a_{-2} b^{-2}+\cdots
\end{aligned}
$$

Por exemplo:

- $\quad(101,011)_{2}=1 \cdot 2^{2}+0 \cdot 2^{1}+1 \cdot 2^{0}+0$. $2^{-1}+1 \cdot 2^{-2}+1 \cdot 2^{-3}$

$$
=4+1+\frac{1}{4}+\frac{1}{8}=\frac{43}{8} \text {; }
$$

- $\quad(21,1111 \ldots)_{3}=(21, \overline{1})_{3}=2 \cdot 3^{1}+1 \cdot 3^{0}+$ $1 \cdot 3^{-1}+1 \cdot 3^{-2}+\cdots+1 \cdot 3^{-i}+\cdots$ $=6+1+\frac{1}{3}+\frac{1}{9}+\frac{1}{27}+\frac{1}{81}+\cdots+\frac{1}{3^{i}}+\cdots$ $=7+\frac{1}{2}=\frac{15}{2}$;

- $\pi=(3,1415 \ldots)_{10}=3 \cdot 10^{0}+1 \cdot 10^{-1}+4$. $10^{-2}+1 \cdot 10^{-3}+5 \cdot 10^{-4}+\cdots$.

Note que, no segundo exemplo, utilizamos um traço para indicar que um determinado grupo de algarismos se repete sucessivamente. Chamaremos estes numerais de representações posicionais periódicas, ao invés de dízimas periódicas, como usualmente se faz para a base 10. Já no terceiro exemplo, não temos nenhum grupo de algarismos que se repete sucessivamente. Teremos que utilizar outro procedimento matemático para determinar quais são os algarismos subsequentes. Então, é importante observar que podemos ter representações posicionais finitas, infinitas periódicas e infinitas não-periódicas. 
Segundo Eves (2004), os mesopotâmicos, por volta do século XIX antes da era cristã, já utilizavam a representação posicional, que aplicavam evidentemente a sua base, a qual era sexagesimal. É assim que um numeral como 0,13 , para eles significaria $1 / 60+3 / 3600=7 / 400$. Porém, como era de se esperar, os mesopotâmicos não dispunham de uma notação simples e clara como a atualmente utilizada no sistema decimal. Para representar suas frações sexagesimais, eles se serviam de algarismos como os que vimos na seção 2 e não dispunham da vírgula para separar a parte inteira da não inteira. As ambiguidades, resultantes da ausência de um símbolo específico com esta finalidade, eram esclarecidas a partir do contexto ou de elucidações feitas oralmente sobre a grandeza dos números, que eram expressos por meio de marcas feitas em tabuletas de argila. Embora os mesopotâmicos tenham utilizado frações posicionais há aproximadamente quatro milênios, este conhecimento, devido às dificuldades de comunicação que existiam no passado, acabou se perdendo.

Segundo Rooney (2012), em 1522, na Alemanha, Adam Riese (1489-1559) publicou uma tabela, na qual utiliza frações decimais para expressar o valor de raízes quadradas. Em 1530, Cristoff Rudolff (1500-1545) demonstrou dominar o uso dessas frações, utilizando uma barra vertical ao invés da vírgula. Todavia, o primeiro tratado europeu sobre frações decimais foi escrito em 1585, pelo flamengo Simon Stevin (1548-1620), que utilizou, entretanto, uma notação pouco prática.

O mesmo autor afirma que o uso do ponto para indicar a parte inteira parece ter-se estabelecido quando John Napier (1550-1617) publicou suas tabelas de logaritmo utilizando esta notação. Em 1617, ele teria sugerido o uso deste ou da vírgula, e optado pelo ponto em 1619. Atualmente, embora no Brasil seja consagrado uso da vírgula para separar a parte inteira da não inteira, há países como Inglaterra e Estados Unidos que utilizam o ponto com esta finalidade, como pode ser facilmente constatado em muitas calculadoras.

A seguir, apresentamos uma série de perguntas e respostas que sintetizam a teoria envolvida na representação dos reais em um sistema posicional de base $b$ e que podem ser utilizadas para guiar os estudos e pesquisas sobre o tema:

- Toda representação posicional está associada a um único numero real? Sim. Uma representação posicional está associada à soma da série

$$
\sum_{i=-n}^{\infty} a_{i} b^{-i}
$$

que é convergente, por conta da completude dos reais;

- Uma representação posicional finita está associada a um número racional ou irracional? Está associada a um número racional, pois é a soma de números racionais;

- Uma representação posicional infinita periódica está associada a um número racional ou irracional? Está associada a um número racional, pois teremos a soma infinita de uma progressão geométrica de razão $\frac{1}{b^{p}}$, cujo limite é um número racional;

- Uma representação posicional infinita não-periódica está associada a um número racional ou irracional? Está associada a um número irracional, pois um número racional possui uma representação posicional finita ou infinita periódica;

- Todo número real possui uma representação posicional? Sim.

- Esta representação posicional é única? Não. Todo número racional não-nulo possui uma representação posicional infinita periódica. Alguns números racionais possuem uma representação posicional finita também.

- Como obter uma representação posicional para um determinado número real? Quando o número é racional, os algarismos são obtidos pelo algoritmo da divisão, quando dividimos o numerador e o denominador da fração correspondente. Quando o número é irracional, devemos aproximá-lo por racionais de representação posicional finita. A parte inteira e os primeiros $m$ algarismos da parte não-inteira de um número real positivo $\mathrm{x}$ são iguais aos do maior racional que seja menor ou igual a $x$, dentre os racionais que possuem representação posicional finita com $\mathrm{m}$ 
algarismos na parte não-inteira. Neste ponto, a abordagem geométrica será muito útil.

- Todo número racional possui uma representação posicional finita? Não.

- Quando um número racional possui uma representação posicional finita? Apenas quando o número racional é igual à fração irredutível $\mathrm{p} / \mathrm{q}$, onde $\mathrm{q}$ possui apenas fatores primos que são fatores primos de b. Alguns exemplos deste fato podem ser encontrados na Tabela 1.

- Um número racional possui que tipo de representação posicional? Possui representação finita ou infinita periódica. Ao calcular os algarismos da representação, por meio do algoritmo da divisão, se obtivermos em algum dos passos um resto igual a 0 , teremos uma representação finita. Caso contrário, os restos se repetirão periodicamente $\mathrm{e}$ teremos uma representação infinita periódica.

- Um número irracional possui que tipo de representação posicional? Possui uma representação infinita não-periódica, pois as representações finita e infinita periódica estão associadas a números racionais.

Tabela 1: Representação posicional de algumas frações próprias em diferentes sistemas de numeração.

\begin{tabular}{lllllll}
\hline base & $\mathbf{1} / \mathbf{2}$ & $\mathbf{1 / 3}$ & $\mathbf{3} / \mathbf{4}$ & $\mathbf{2 / 5}$ & $\mathbf{5 / 6}$ & $\mathbf{4} / \mathbf{7}$ \\
\hline $\mathbf{2}$ & $0, \overline{1}$ & $0, \overline{01}$ & $0, \overline{11}$ & $0, \overline{0110}$ & $0, \overline{110}$ & $0, \overline{\overline{100}}$ \\
$\mathbf{3}$ & $0, \overline{1}$ & $0, \overline{1}$ & $0, \overline{20}$ & $0, \overline{\overline{1012}}$ & $0,2 \overline{1}$ & $0, \overline{12010}$ \\
$\mathbf{4}$ & $0, \overline{2}$ & $0, \overline{1}$ & 0,3 & $0, \overline{12}$ & $0,3 \overline{1}$ & $0, \overline{210}$ \\
$\mathbf{5}$ & $0, \overline{2}$ & $0, \overline{13}$ & $0, \overline{3}$ & 0,2 & $0, \overline{40}$ & $0, \overline{24120}$ \\
$\mathbf{6}$ & $0, \overline{3}$ & 0,2 & 0,43 & $0, \overline{2}$ & 0,5 & $0, \overline{32}$ \\
$\mathbf{7}$ & $0, \overline{3}$ & $0, \overline{2}$ & $0, \overline{51}$ & $0, \overline{2541}$ & $0, \overline{5}$ & 0,4 \\
$\mathbf{8}$ & 0,4 & $0, \overline{25}$ & 0,6 & $0, \overline{3146}$ & $0,6 \overline{52}$ & $0, \overline{4}$ \\
$\mathbf{9}$ & $0, \overline{4}$ & 0,3 & $0, \overline{6}$ & $0, \overline{35}$ & $0,7 \overline{4}$ & $0, \overline{512}$ \\
$\mathbf{1 0}$ & $0, \overline{5}$ & $0, \overline{3}$ & 0,75 & 0,4 & $0,8 \overline{3}$ & $0, \overline{57142}$ \\
$\mathbf{1 1}$ & $0, \overline{5}$ & $0, \overline{37}$ & $0, \overline{82}$ & $0, \overline{4}$ & $0, \overline{91}$ & $0, \overline{631}$ \\
$\mathbf{1 2}$ & 0,6 & 0,4 & 0,9 & $0, \overline{4972}$ & $0, A$ & $0, \overline{6 A 351}$ \\
\hline
\end{tabular}

\section{Atividades para Educação Básica}

A História da Matemática, além de ser naturalmente atrativa e curiosa, é um vasto campo de pesquisa que pode ser utilizado pelo professor para estimular o interesse dos alunos.
Pesquisando fatos históricos o aluno se depara com a necessidade de aprimorar seus conhecimentos em assuntos próprios da área do conhecimento a que esses fatos se referem, neste caso, à Matemática. Quando vistos a partir de uma perspectiva histórica, até mesmo os conteúdos mais áridos parecem ganhar vida, passando a ganhar significado para o aluno. Aqui o professor tem muitas possibilidades para conduzir o aluno até o mundo da pesquisa, desenvolvendo nele a autonomia, estimulando sua curiosidade e independência na busca do conhecimento.

Pode-se solicitar aos alunos que pesquisem a história de grandes matemáticos do passado que se envolveram com a difusão do sistema de numeração indo-arábico, como Fibonacci ou alKhowarizmi, ou ainda, em uma atitude interdisciplinar, pedir que pesquisem um pouco da história e da cultura das grandes civilizações do passado, buscando conhecer melhor que tipo de conhecimento matemático foi produzido por tais povos.

Como sugestão de atividade de pesquisa relacionada ao conhecimento matemático trabalhado neste artigo, o professor pode pedir que seus alunos investiguem sobre a classificação dos sistemas de numeração, utilizando como fontes a internet, a biblioteca da universidade ou da própria escola.

Outra pesquisa interessante, relacionada ao conceito de base de um sistema de numeração, consiste em propor que os alunos pesquisem quais foram as bases mais utilizadas ao longo da história, quais povos as utilizaram e qual a razão de terem sido tomadas ao invés de outras.

Propomos o ensino dos sistemas de numeração posicionais como um meio para a compreensão dos algoritmos que utilizamos para efetuar as quatro operações. Não é de nosso conhecimento que as explicações sobre o porquê, e não apenas de como, estes algoritmos funcionam, mesmo quando bem trabalhadas nas séries iniciais, sejam revisitadas posteriormente na educação básica.

Sugerimos a utilização de calculadoras científicas para estudar a representação de números em outras bases. Algumas delas possuem a tecla $\mathrm{a}^{\mathbf{b} / \mathrm{c}}$ que apresenta a divisão entre dois inteiros na forma de número misto, essa tecla pode ser utilizada para facilitar a mudança de base através do método das 
divisões sucessivas, desde que façamos com que o aluno perceba que a parte inteira do número misto é o quociente da divisão e que o numerador da fração própria é o resto da divisão. Assim, se escrevermos na calculadora o número 46, apertarmos tal tecla, escrevermos o número 8, e apertarmos a seguir a tecla de igualdade, aparecerá no visor o número misto $5 \frac{3}{4}$.

O professor pode, por exemplo, depois de dado algumas explicações sobre sistemas de numeração posicionais, em particular sobre o sistema binário, pedir que seus alunos pesquisem sobre "linguagem de máquina" na Internet, para que estes descubram por si sós a relação existente entre o sistema binário e a informática, compreendendo que muitos conteúdos matemáticos possuem realmente aplicações no mundo em que vivemos e que isso independe do professor mencionar ou não essas aplicações em sala de aula. Feita essa pesquisa pelos alunos, o professor pode resgatar os resultados e explanar sobre as aplicações dos sistemas binário, octal e hexadecimal no campo da informática, bem como mencionar a presença do sistema sexagesimal na contagem do tempo e na medição de ângulos.

Outra atividade interessante para ser desenvolvida com os alunos em sala de aula, depois de explicar o método das divisões sucessivas, é pedir que estes convertam um número relativamente alto para diversas bases, postas em ordem crescente a partir da base 2, pedindo que descrevam o que está acontecendo. Os alunos devem chegar sozinhos à conclusão de que quanto menor é a base mais extensa se torna a representação dos numerais.

Pensamos que uma boa estratégia para trabalhar este tema seria envolvendo-o como parte de um projeto mais amplo sobre sistemas de numeração, o qual poderia ser trabalhado com um grupo de alunos dentro de um clube de Matemática ou na forma de um trabalho para ser apresentado na feira de ciências da escola.

Se estivermos lidando com um grupo de alunos que já compreenderam o funcionamento dos sistemas posicionais e que já dominam a escrita de números naturais em outras bases, seria possível pedir que escrevessem os 20 ou 30 primeiros números na base 6 , perguntando se notam aí algum padrão para os múltiplos de 3 .
Depois de fazer o mesmo com a base 8 e pedir que observem os múltiplos de 4 . É bem possível que percebam que o mesmo ocorrerá para os múltiplos de 6 na base 12. Os alunos então passariam, eles próprios, a procurar padrões.

Outra sugestão que damos para o professor é que faça um resgate de temas simples e importantes como os critérios de divisibilidade e a prova dos nove.

O Projeto Klein, que é uma iniciativa da Sociedade Brasileira de Matemática (2013), conduz alunos ao estudo de conhecimentos matemáticos mais profundos a partir de temas simples da educação básica. O tema abordado neste artigo está de acordo com essa proposta, pois de temas extremamente simples como sistemas de numeração e critérios de divisibilidade chega-se ao estudo de temas relacionados à Teoria dos Números.

E, quando se trata de fazer com que os alunos compreendam a representação posicional dos números reais, podemos utilizar novamente as calculadoras científicas. É uma oportunidade de discutir com os alunos sobre a utilização do ponto, ao invés da vírgula, como separador das partes inteira e não inteira do número em sua forma decimal, abordando além do significado da vírgula, a questão da diferença de notação que existe entre diversos países na representação das frações decimais.

Os procedimentos que devem ser utilizados para encontrar as frações geratrizes de dízimas periódicas e de decimais exatos podem ser perfeitamente descobertos pelo próprio aluno a partir de atividades orientadas pelo professor com o uso da calculadora. O professor pode, por exemplo, pedir que seus alunos efetuem, na calculadora, contas como 5/9, 7/9, 45/99, 387/999, solicitando que estes digam o que percebem, depois pode ir ao quadro e colocar uma dízima periódica do tipo $0,444 \ldots$ e pedir que estes tentem deduzir a fração ordinária que deu origem a dízima, ou seja, sua fração geratriz.

O professor terá ainda a chance de discutir com seus alunos o fato de que, embora a calculadora tenha um limite de dígitos para ser exibido no visor, o período das dízimas periódicas se repete infinitamente, além de questões relacionadas a arredondamentos, explicando, por exemplo, porque embora o professor insista em dizer que $2 / 3=0,666 \ldots$, a sua 
máquina teima em mostrar o resultado 0,666666667. É a chance de mostrar para seus alunos a importância de ter o conhecimento teórico para compreender erros.

Além disso, o professor pode mostrar para seus alunos que, embora possamos utilizar a notação posicional para representar dízimas periódicas e irracionais, na prática, não operamos com estes números, mas com suas aproximações a partir de decimais exatos. Pode comentar ainda como é possível, a partir dos decimais exatos, obter aproximações tão boas quanto desejemos para dízimas periódicas e irracionais.

Além disso, a representação posicional dos números reais nos fornece um meio acessível de explicar para nossos alunos sobre a diferença entre números irracionais e números racionais sem cair em um pensamento cíclico.

\section{Conclusões}

A Matemática não se desenvolveu pela presença de pessoas iluminadas, as únicas capazes de enxergar aquilo que outros estariam privados de ver, e sim pelo esforço e trabalho árduo de diversas gerações de seres humanos empenhados em resolver problemas que se apresentaram diante deles e que precisavam ser superados, problemas estes, muitas vezes resolvidos com engenho e criatividade, por povos distanciados muitas vezes tanto cronológica quanto geograficamente, mas que acabavam encontrando soluções parecidas para os mesmos problemas.

No campo educacional, ver as dificuldades que os povos enfrentaram ao tentar encontrar maneiras eficazes para representar e operar com os números, dificuldades estas que necessitaram de milênios para serem superadas, torna-nos mais tolerantes quando vemos nossos alunos esbarrando nessas mesmas dificuldades.

No âmbito dos sistemas de numeração posicionais, devemos estar convencidos de que a escolha de uma base decimal não se deve ao fato de a dezena possuir propriedades especiais que a permitem melhor representar os números, mas a forma de nossas mãos, com cinco dedos em cada uma. Além disso, por tudo que foi visto a respeito de sistemas posicionais, fatos que pareciam ser propriedades intrínsecas aos números, como os critérios de divisibilidade e a periodicidade, revelam-se como propriedades da relação entre estes números e a base do sistema de numeração que os está representando.

Mas a razão que, para nós, justifica a profundidade com que abordamos o tema dos sistemas de numeração, cuja importância já está mais do que demonstrada, é a nossa crença no fato de que o professor deve conhecer mais do que seus alunos a respeito daquilo que ensina.

\section{Agradecimentos}

O primeiro autor (Aroldo Eduardo) gostaria de agradecer à CAPES pelo suporte financeiro quando cursava o PROFMAT pela Universidade Federal do Oeste do Pará.

\section{Referências}

EVES, Howard. Introdução a História da Matemática. Campinas: Editora da UNICAMP, 2004.

IFRAH, Georges. Os números: a história de uma grande invenção. 11. ed. São Paulo: Globo, 2005.

. História universal dos algarismos. Rio de Janeiro: Nova Fronteira, 1997. v.1.

RODRIGUES, Aroldo. Sistemas de numeração: evolução histórica, fundamentos e sugestões para o ensino. Dissertação de Mestrado Profissional em Matemática. Universidade Federal do Oeste do Pará, Santarém, 2013.

ROONEY, Anne. A História da Matemática: desde a criação das pirâmides até a exploração do infinito. São Paulo: M.Books do Brasil Editora Ltda, 2012.

SANTOS, Camargo. Números reais: um desafio na educação básica. Monografia de Especialização em Matemática. Universidade Federal Fluminense, Niterói, 2007.

SOCIEDADE BRASILEIRA DE MATEMÁTICA. Projeto Klein de Matemática em língua portuguesa. 2013. Disponível em: <http://klein.sbm.org.br> Acessado em: 27 dezembro 2014. 